\title{
Survey and research frame for ground sediment
}

\author{
Jichao Sun ${ }^{1}$
}

Received: 20 May 2016 / Accepted: 8 August 2016/Published online: 23 August 2016

(C) Springer-Verlag Berlin Heidelberg 2016

Sediment from the fine particles forming rock fragmentation is composed of soil and sand. Sediment is carried by water into the river and sea and silt rivers and ports. Sediment taken into the air by wind becomes the dust and haze. Sediment has been closely linked with the human life, and forming many disasters more closely impacting the human life. Sediment is mainly from the land and river, as well as sediment from the underground called "ground sediment." Sediment, hidden in the underground, is not known to people. The sediment particle transport in soils by water scouring can be found in the reference Sun (2016). Some or one soil particle runs in a crack and passageway between soil particles. In the process, soil particles perhaps form new structures or passageways. Ground sediment deeply affects human life, such as sediment attracted and driven by the water is becoming the heaving pit (Fig. 1a.), heaving mound (Fig. 1b.), heaving mound on Mars (Fig. 1c.) and some riverbanks collapse (Sun 2014a, b); while the ground sediment transport can also cause damage and collapse of the riverbank and embankment, building, and ground subsidence. The current studies are less involved in the transport and movement of the ground sediment. Therefore, strengthening the ground sediment study has an important, practical, and theoretical value.

Responsible Editor: Philippe Garrigues

Jichao Sun

Jichao@email.com; sjc00@126.com

1 School of Water Resource \& Environment, China University of Geosciences, Beijing 100083, China

\section{Three levels of sediment}

The former research on the sediment is focused on river sediments as shown in Fig. 2a,, which are studied in the river in order to obtain the river ability to erode sediment, the sediment distribution along the river length, and the depth. Research from previous years has risen from the river channel to the land, that is from the river channel sediment (as shown in Fig. 2a.) to the land sediment (as shown in Fig. 2b.). One typical research of this is the digital watershed model (Formetta et al. 2014). It takes the sediment movement driven by the rainfall as the main research contents to obtain the erosion spatial and temporal distribution. Many researches (Cessna et al. 2006; Odgaard 1993; Riccio et al. 2014; Serno et al. 2014) focused on the wind sediment, which is driven by wind and belongs to the surface sediment.

The latest research will further improve the sediment research content. The surface sediment is extended to the ground. One part of the river sediment is from the river bottom and sides, and the other part is from the land surface, the watershed sediment studied, the sediment of which is located on the earth surface; and. therefore, can be called surface sediment, as shown in Fig. 2a, b.. There is also a significant source of sediment: internal riverbank and under land, which is from the underground and can be called ground sediment (Sun 2015, 2016; Sun \& Wang 2013; Wang et al. 2010, 2011), as shown in Fig. 2c.. Research on ground sediment is a new research area, and the typical performance in this area is the riverbank stability reduction and collapse by the ground sediment transport under the scouring and the fluctuation water level.

The ground sediment existence and transport can cause a lot of engineering problems, as shown in Fig. 3. The ground sediment transport under the fluctuation water level in 
Fig. 1 The Ground uplift caused by ground sediment transport. a Milwaukee road heaving pit. b Pingo on the earth. c The pingos on Mar HiRISE image: ESP014,413-2065
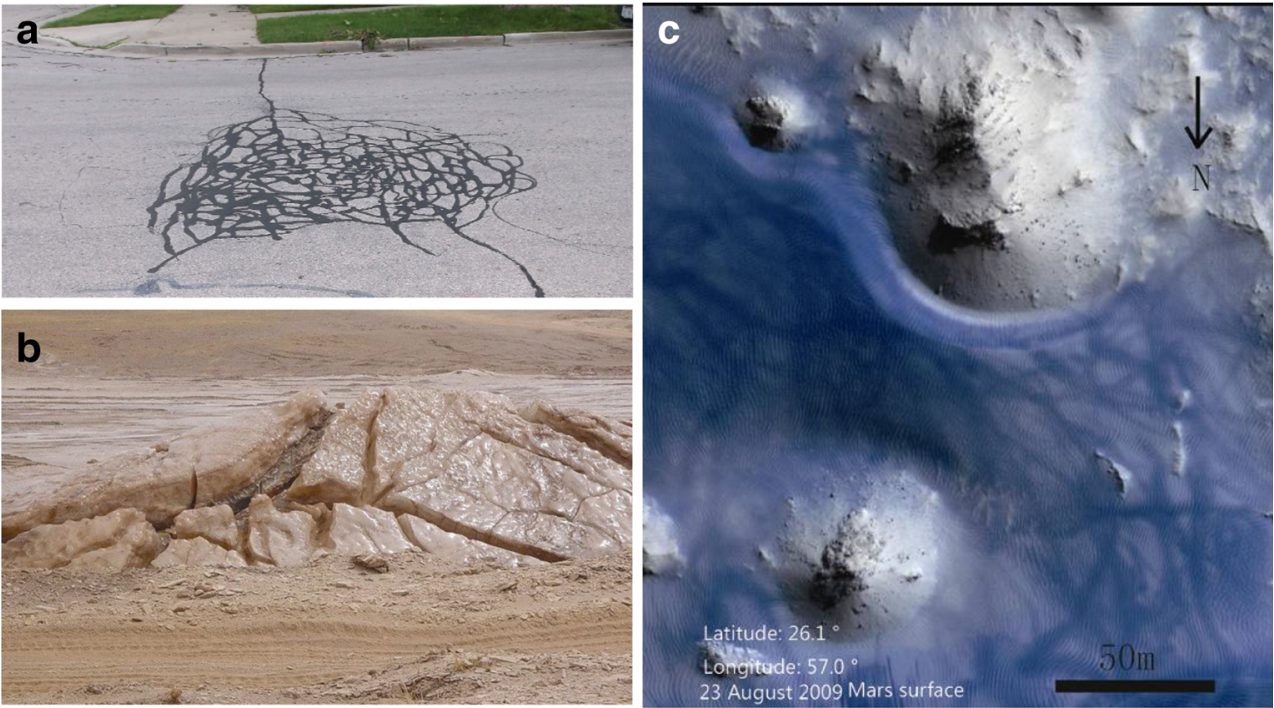

riverbank may eventually lead to the collapse of the dam embankment. The groundwater with the changing level drives the ground sediment transport leading to the ground subsidence. The heave driving sediment transport causes the heaving mound to grow, as shown in Fig. $1 \mathrm{~b}$ and collapse as shown in Fig. 1a.. Heaving mound is found not only on the earth but also on Mars (Burr et al. 2009; de Pablo and Komatsu 2009; Dundas and McEwen 2010), as shown in Fig. 1c. Sediment in faults and fractures under the external disturbance, such as earthquakes and water level fluctuations, is transported. This transportation leads to the activation of faults and fissures. The groundwater exploitation driving the ground sediment transport leads the groundwater fissure to be blocked and to prolong the water supply. The ground sediment transport with the water and oil leads the oil fissures to be blocked and cause the oil flow velocity to decrease, etc. These are likely to lead to

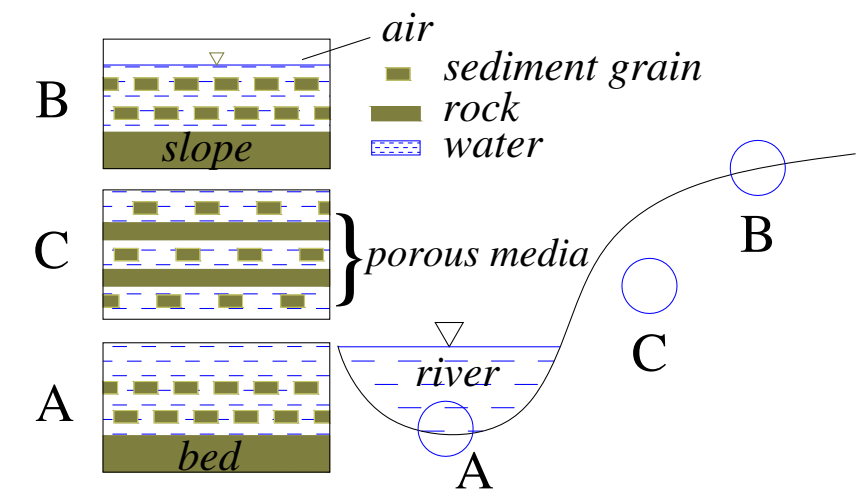

Fig. 2 The three levels of ground sediment. a River channel sediment. b Surface sediment. c Ground sediment some major accidents or increase the running costs, which are directly related to the underground sediment transport.

\section{Sediment transport in unsaturated soils}

Soils can be classified as saturated or unsaturated based on their water content. The ground sediment transport has two types, sediment transport in saturated and unsaturated soils. Sun and Wang (2013) studied the sediment transport in soils and established the transport model of ground sediment in soils. This model starting the mathematical model from the ground sediment concept is the stable sediment transport in saturated soils. The model is very significant. Rising or falling river water levels cause water to move laterally to or oppose the riverbank. Rainfall causes water to infiltrate into soils. The rising or falling ground water level causes water to move up or down. The migration of water in soils changes the water content. The ground sediment movement carried by water is called the water and sediment movement in unsaturated soils. These physical phenomena, called forward and reverse movement of water and sediment, are related to the reciprocating movement of water and sediment in horizontal and vertical direction.

The ground sediment reciprocating transport contains the soil damage and recovery. Sediment erosion in water results in the loss of soil, so the porosity in sand position increases and the intensity and strength reduce, which can be called damage. When the water flow direction is reversed and the sediment movement is reversed, the original soil strength is enhanced, which can be called recovery (Kakuturu \& Reddi 2006), 
Fig. 3 Classification of sediment and engineering problems

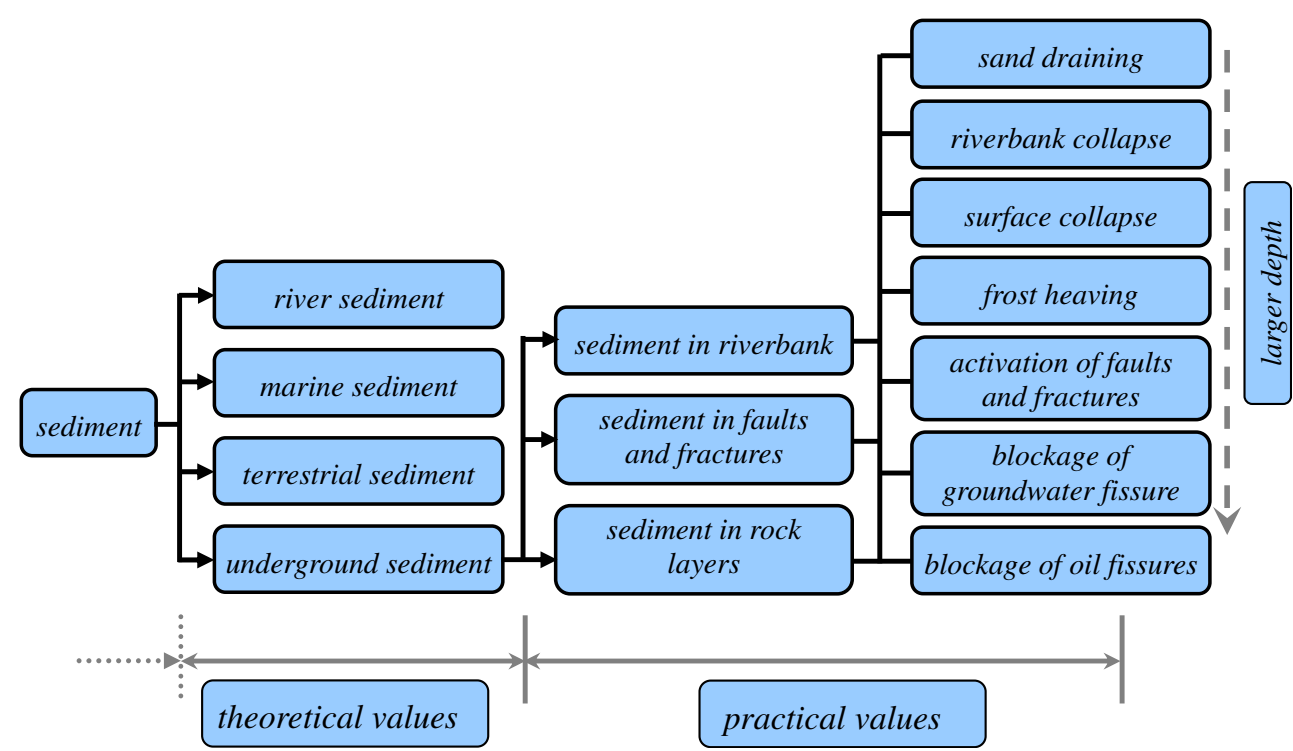

because the strength where the sediment gathers is higher than the location of the sand sediment washed away.

Research on sediment transport in the unsaturated soil contains the unsaturated soil infiltration and sediment transport.

Studies on unsaturated soil infiltration have made great achievements. The Richards equation is obtained in the study of the fluid capillary conduction in porous media (Richards 2004). The following researches are based on the equation (Guerif et al. 2001). References (Topp et al. 1980) obtained the permeability coefficient by fitting and taking moisture as a variable. In the paper (Van Genuchten 1980), the water pressure and moisture can be taken to build a function to determine the relative hydraulic conductivity. Some recent studies focused on the following aspects: (1) The method of solving equations, such as the finite element calculation (Tayfur et al. 2010a, b), (2) the solute and water content measurement studies on site (Reichman et al. 2011; Stumpp \& Hendry 2012), (3) unsaturated soil monitoring methods (Saintenoy \& Hopmans 2011), (4) solving theory (Sun \& Wang 2010), (5) the effect of temperature on water flow (Jahangir \& Sadrnejad 2012; Sun et al. 2006), and so on. These are the theoretical or experimental researches of the Richards equation parameters.

Researches on the sediment transport in the unsaturated soil are few, but are mainly concentrated in the river sediment study. On the sediment particles transport in water, major research papers are (Einstein 1950; Qiwei 2007). These studies greatly founded the basement of the non-uniform particle sediment transport researches, and ingeniously explained the different size particle movement of sediment scoured by river water. The practical applications of these theories include the river channel sediment start (Yang et al. 2009), the sediment saturation and numerical simulation (Guo et al. 2012), and the watershed sediment ( $\mathrm{Li}$ et al. 2012). These studies can provide the important reference value for unsaturated soil sediment transport studies. The closest researches in this area are from Sun JC (Sun 2013; Sun \& Wang
2013; Wang et al. 2010, 2011), who studied the process of the saturated steady water flow driving ground sediment, proposed the sediment transport equation, and obtained the sediment content evolution along the way.

Sediment transport studies in the unsaturated soil need to be focused on the breakthrough of the coupling relationship between the water flow and sediment transport in unsaturated soil, and on the proposed coupling parameters and equations, and on establishing high efficient numerical simulation methods. The reference (Sun \& Wang 2013) studied the process of the saturated groundwater driving the ground sediment transport, obtained the sediment transport equation, and gave the numerical simulation. The author gave suggestion that some experimental equipment should be founded and further experiments should be made. About equipments testing saturated sediment has emerged, patents (Wang et al. 2010, 2011) give the direct method to measure the ground sediment transport after scouring and eroding. The patent (Sun 2013) presented the method and experimental concept in the process of the ground sediment blocking and dredging the rock fracture driven by the ground water. A comprehensive study can be conducted through experiments and numerical simulation in this area. Many research works (Davis and Fox 2009; Walling 2005) used the tracer method to study the source regions of dust, which obtained the success. The ground sediment research can reveal the geology phenomena, such as the rock and soil lay's distributions, connecting with the tracer method.

\section{Fluctuating transport of ground sediment}

Ground sediment involves a lot of physical phenomena and needs to be understood and scientifically explained, one of which is the fluctuation of the ground sediment transport. 
Water, sand, and soil are involved in the interaction process between water and sediment. In the seepage process, the velocity is proportional to the hydraulic gradient, like the curve shown in Fig. 4a. meeting Darcy's law (Gutman \& Davidson 1975) $v=k \Delta h / L . \Delta h$ is the flushing water pressure head, $v$ is the flow velocity, $k$ is the permeability coefficient, $\Delta h$ is the water pressure difference, and $L$ is the path length of the infiltration from the inlet to the outlet.

Soils are made up of a lot of sand and sand particles between each bite mosaic with a certain strength. The seepage appears under the water pressure and meets Darcy's law (Neuman 1977), according to which the flow velocity is proportional to the hydraulic gradient, as shown in Fig. 4. At this time, the mosaic resistance between particles is much larger than the water flow pressure (Espinoza and Santamarina 2010), so, there is only water seepage. With the water pressure increase, the water seepage erosion force increases. The tiny particles move with water when the erosion force becomes greater than the mosaic resistance, as shown in Fig. 4b,c., which is called percolation.

When the water pressure gradually increases, the fine soil particles pass through the pores between the large particles, and at this time the transport channel is not stable. The space vacated by the small particles carried away by water is a part of the flow channel. The space is so big that it causes the surrounding soils to be damaged and collapsed and the void ratio and flow velocity to increase (Indraratna and Radampola 2002), and at last, more particles go into the water flow.

In the course of the small particles first transport moving forward, if the particle diameter is bigger than that of the pore channels, small particles will clog the channel, and the water flow rate will be reduced, thereby, the sediment transport capacity will reduce. When sediment blocks the pore channel along the way, because the congestion is a gradual process, the resistance at the location of blockage increases. When the flow rate becomes zero, all the head pressure $\Delta \mathrm{h}$ is applied to the clogging particles, and this blockage and cumulative water pressure increases gradually. When the water pressure is greater than the clogging particles resistance, the clogging particles will break through the blockage and move forward. This process is different from the fluctuations in the river channel sediment (Mu et al. 1999). This pressure is an increasing and decreasing process with stages in terms of time and segments along the way, so the seepage water pressure is fluctuant. The water pressure at a point in terms of time also has a continuous fluctuating characteristics with accumulating and breakthroughs, so it can be called multi-amplitude sediment transport. Also, along the way, the sediment concentration and its change with time are also fluctuating, as shown in Fig. $4 \mathrm{~b}$. When the flow path is less than half a wavelength, it becomes the single amplitude sediment transport, as shown in Fig. 4b. In this transport process, there is no accumulated or clogging phenomenon, but the water pressure directly breaking through soils. Therefore, the single amplitude sediment transport is a special case of the multi-amplitude transport. Sun $(2013,2015)$ separately studied the mathematical model coupling seepage and sedimentation of solid particles in porous media and the experiment method. Sun (2015) established the block model of ground sediment by numerical example, which can analyze and explain the natural reason of ground sediment fluctuating transport, because the fluctuating transport blocks and dredges the crack and passageway one by one and step by step.

\section{Dumbbell-shaped mode of the ground sediment transport}

In the ground sediment transport process, the sediment and water seepages appear progressively, which is similar to the riverbank degradation (Rinaldi \& Nardi 2013). We find that the outlet greatly impact on the water and sediment seepage, and even decisively.

In the process of the river water and sediment transport in the river, when water rises to break the riverbank, a new secondary channel and secondary river will be formed (He et al. 2013). In the same way, when the secondary river channel is broken, the new third river channel appears. In this process, the sediment is transported with water. This phenomenon is called river channel diffusion, as shown in Fig. 5a.
Fig. 4 Three stages of ground sediment transport

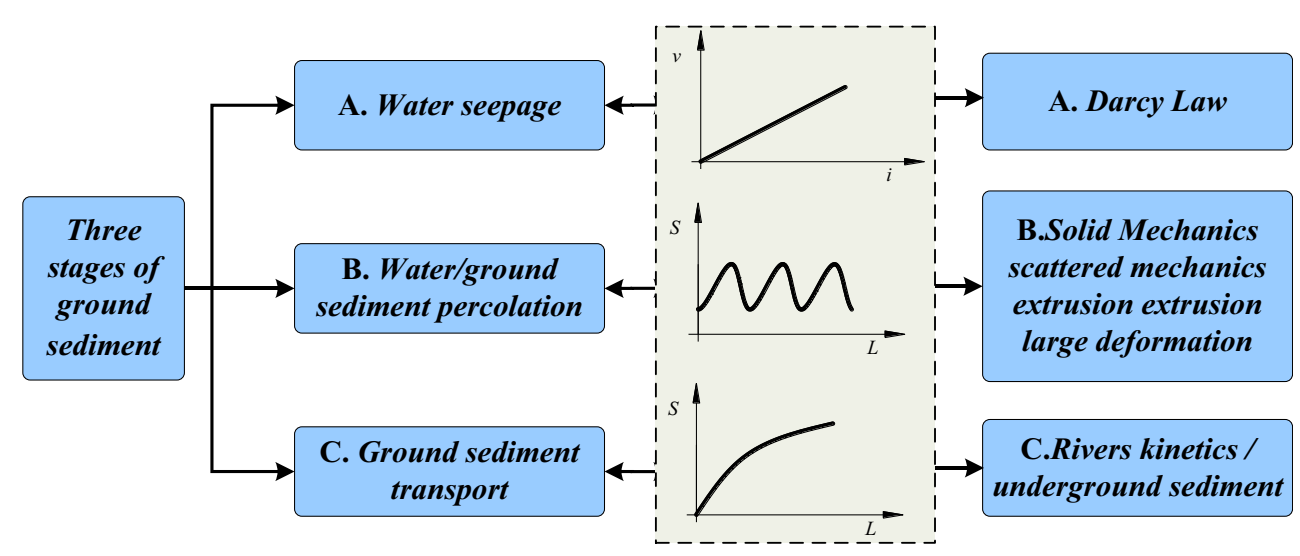




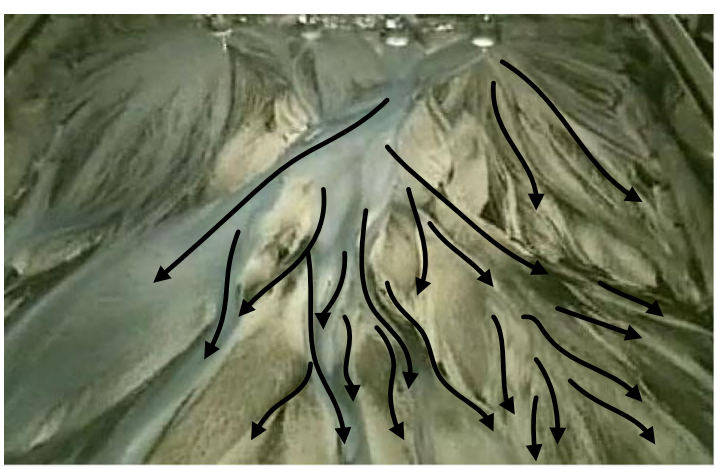

A River spread phenomenon

(Chris Paola)

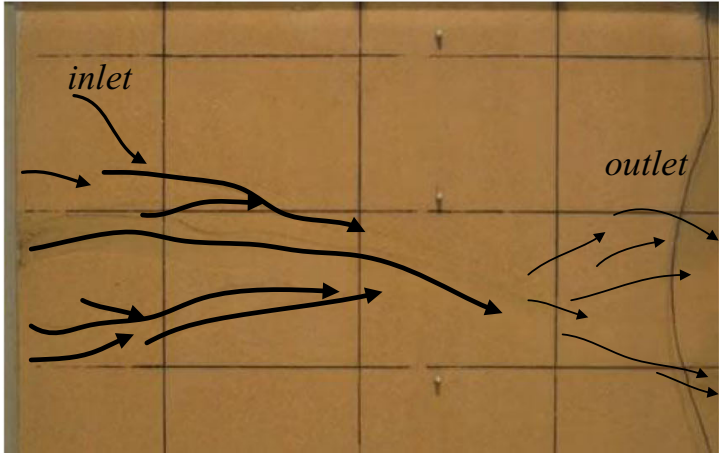

B underground channel Dumbbell phenomenon (experiment at Deltares, Delft)

Fig. 5 River spread phenomenon and ground sediment dumbbell phenomenon

The transport is even in the early stage of the ground sediment transport. But with time going on, the non-uniform transport firstly appears at the outlet, and the new outlet channels are scattering (PSUDianaC 2011-03-11), as shown in Fig. 5b. At the outlet, the soil strength is weakened due to the water penetration (Sun \& Wang 2010), while the scattering collapse appears at the outlet without any lateral support (PSUDianaC 2011-03-11).

The entrance is uniform, while the outlet randomly appears. When the outlet has some small destroyed exports (Chu-Agor et al. 2009), the channel to the outlet can become the main channel, so the sediment aggregation phenomenon appears at the entrance. Plenty of water and sediment aggregate into the main channel, resulting in an increase of the speed and flow of water and sediment, while a decrease in other places. And this process leads to further damages, as shown in Fig. 5b, in which the aggregation phenomenon can be found at the entrance.

Scattering collapse at the outlet and clustering effect on the entrance, form a dumbbell-shaped ground sediment transport phenomena, which can be called dumbbell-shaped mode of the ground sediment transport.

There are many similarities and differences between the dumbbell-shaped ground sediment transport and the river channel diffusion of the sediment transport, because the pressure of water and sediment dissipates. In this study, observations are the mainly research methods. This physical phenomenon needs to be studied and especially quantified, which has a greatly theoretical value.

\section{Conclusions}

Three different levels of the sediment are given in the paper, which are the river channel sediment, the land sediment, and the ground sediment. The ground sediment is proposed in the paper. The river channel sediment and land sediment belong to the surface sediment, while the ground sediment exists under the surface and is in soils. The existing research in the sediment field is extended. The research direction of the sediment transport in unsaturated soils and progressive transport is pointed out. And the damage and recovery in soils due to the multi-amplitude sediment transport is explained by the mechanism. Several ground sediment physical phenomena are given, such as the ground sediment fluctuation and fluctuating transport. The fluctuating transport is divided into multiamplitude sediment transport and single-amplitude transport, and the single-amplitude transport is the special case of the multi-amplitude transport. The dumbbell-shaped mode of the ground sediment transport is proposed, which is different from the river channel diffusion mode of the sediment transport, and is explained by the mechanism.

The research on the ground sediment is still in its infancy, the current main task is to establish and plan a more comprehensive study framework for the physical phenomena of the ground sediment. The ground sediment transport equation and boundary conditions for numerical calculations should be established. The physical laboratory equipments should be invented, and field observations and measurement should be made in the future. In this way, the research direction can be used to solve the practical problems in hydraulic engineering, transportation, energy exploitation, and so on.

Acknowledgement This work is supported by the National Natural Science Foundation of China (No. 51179177), China State Scholarship Found (No.: 201208110444).

\section{References}

Burr DM, Tanaka KL, Yoshikawa K (2009) Pingos on Earth and Mars. Planetary and Space Science 57:541-555

Cessna AJ, Larney FJ, Kerr LA, Bullock MS (2006) Transport of trifluralin on wind-eroded sediment. Can J Soil Sci 86:545-554 
Chu-Agor ML, Fox GA, Wilson GV (2009) Empirical sediment transport function predicting seepage erosion undercutting for cohesive bank failure prediction. J Hydrol 377:155-164

Davis CM, Fox JF (2009) Sediment fingerprinting: review of the method and future improvements for allocating nonpoint source pollution. J Environ Eng 135:490-504

de Pablo MÁ, Komatsu G (2009) Possible pingo fields in the utopia basin, Mars: geological and climatical implications. Icarus 199:49-74

Dundas CM, McEwen AS (2010) An assessment of evidence for pingos on Mars using HiRISE. Icarus 205:244-258

Einstein HA (1950) The bed-load function for sediment transportation in open channel flows. Technical Bulletin 1-71

Espinoza DN, Santamarina JC (2010) Ant tunneling - a granular media perspective. Granul Matter 12:607-616

Formetta G, Antonello A, Franceschi S, David O, Rigon R (2014) Hydrological modelling with components: a GIS-based open-source framework. Environ Model Softw 55:190-200

Guerif J, Richard G, Durr C, Machet J, Recous S, Roger-Estrade J (2001) A review of tillage effects on crop residue management, seedbed conditions and seedling establishment. Soil Tillage Res 61:13-32

Guo J, Wang H, Xiaohua X, Ma T (2012) Generic 2-D River network modeling of flow and sediment transports. Water Resources and Power 30:101-103

Gutman RG, Davidson JF (1975) Darcy's law for oscillatory flow. Chem Eng Sci 30:89-95

He B, Duan W, Luo P, Takara K, Yamashiki Y (2013) Cause mechanism and GIS based spatiotemporal analysis of anthropogenic environmental disasters in eastern Asia. Journal of Disaster Research Vol 8:171

Indraratna B, Radampola S (2002) Analysis of critical hydraulic gradient for particle movement in filtration. J Geotech Geoenviron 128:347350

Jahangir MH, Sadrnejad SA (2012) A new coupled heat, moisture and air transfer model in unsaturated soil. J Mech Sci Technol 26:36613672

Kakuturu S, Reddi LN (2006) Evaluation of the parameters influencing self-healing in earth dams. J Geotech Geoenviron 132:879-889

Li D, Fan Y, Bai L (2012) Research on sedimentation mathematical model of Miaogong reservoir, remote sensing, environment and transportation engineering (RSETE). IEEE 1-4

Mu YK, Cheng AHD, Badiey M, Bennett R (1999) Water wave driven seepage in sediment and parameter inversion based on pore pressure data. Int J Numer Anal Met 23:1655-1674

Neuman SP (1977) Theoretical derivation of Darcy's law. Acta Mech 25: $153-170$

Odgaard BV (1993) Wind-determined sediment distribution and Holocene sediment yield in a small, Danish, kettle lake. J Paleolimnol 8:3-13

PSUDianaC (2011-03-11): Stream Table in class

Qiwei H (2007) Theoretical study of nonequilibrium transportation of nonuniform suspended load. Water Resources and Hydropower Engineering 38:14-23

Reichman R, Rolston DE, Yates SR, Skaggs TH (2011) Diurnal variation of Diazinon volatilization: soil moisture effects. Environ Sci Technol 45:2144-2149

Riccio A, Chianese E, Agrillo G, Esposito C, Ferrara L, Tirimberio G (2014) Source apportion of atmospheric particulate matter: a joint Eulerian/Lagrangian approach. Environ Sci Pollut Res 21:13160 13168
Richards LA (2004) Capillary conduction of liquids through porous mediums. J Appl Phys 1:318-333

Rinaldi M, Nardi L (2013) Modeling interactions between riverbank hydrology and mass failures. J Hydrol Eng 18:1231-1240

Saintenoy A, Hopmans JW (2011) Ground penetrating radar: water table detection sensitivity to soil water retention properties. IEEE J Sel Top Appl Earth Observ Remote Sens 4:748-753

Serno S, Winckler G, Anderson RF, Hayes CT, Mcgee D, Machalett B, Ren H, Straub SM, Gersonde R, Haug GH (2014) Eolian dust input to the Subarctic North Pacific. Earth Plan Sci Lett 387:252-263

Stumpp C, Hendry MJ (2012) Spatial and temporal dynamics of water flow and solute transport in a heterogeneous glacial till: the application of high-resolution profiles of delta $\mathrm{O}-18$ and delta $\mathrm{H}-2$ in pore waters. J Hydrol 438:203-214

Sun J (2013) Simulation test device for the crack block and dredge effect by ground sediment, China

Sun J (2014a) Three Stages Collapse Connection of Riverbank. Int J Ground Sediment Water 1:1-4

Sun J (2014b) The phenomenon of the floating riverbank collapse by water scouring. Int J Ground Sediment Water 1:5-8

Sun J (2015) Mathematical model coupling seepage and sedimentation of solid particles in porous media. Fresenius Environ Bull 24:17351741

Sun J (2016) Ground Sediment Transport Model and Numerical Simulation. Pol J Environ Stud 25:1691-1697

Sun JC, Wang GQ (2010) Riverbank collapse mechanism under scouring. VDM Publishing House, Germany

Sun JC, Wang GQ (2013) Transport model of underground sediment in soils. Journal, Scientific World

Sun JC, Gao QC, Wang HB, Li YM (2006) Numerical simulation of coupled rainfall and temperature of unsaturated soils. Key Eng Mater 306-308:1433-1438

Tayfur G, Tanji KK, Baba A (2010a) Two-dimensional finite elements model for selenium transport in saturated and unsaturated zones. Environ Monit Assess 169:509-518

Tayfur G, Tanji KK, Baba A (2010b) Two-dimensional finite elements model for boron management in agroforestry sites. Environ Monit Assess 160:501-512

Topp G, Davis J, Annan AP (1980) Electromagnetic determination of soil water content: measurements in coaxial transmission lines. Water Resour Res 16:574-582

Van Genuchten MT (1980) A closed-form equation for predicting the hydraulic conductivity of unsaturated soils. Soil Sci Soc Am J 44: 892-898

Walling DE (2005) Tracing suspended sediment sources in catchments and river systems. Sci Total Environ 344:159-184

Wang G, Sun J, Fu X, Wei J, Wu B (2011) An underground sand erosion model experimental apparatus and method, China, patent number: 200910092249.9, Authorization date: 20110511

Wang G, Sun J, Fu X, Wei J, Wu B (2010) Underground sand erosion model experimental apparatus, China, patent number: 200920222614.9, Authorization date: 20100623

Yang F-G, Liu X-N, Huang E, Yang K-J, Cao S-Y (2009) Study on the incipient velocity of Tangjiashan Barrier lake downstream area sediment. Journal of Sichuan University (Engineering Science Edition) 41:84-89 